\title{
Does Peirce Reject Transcendental Philosophy?
}

\author{
Gabriele Gava \\ Piazza Vittorio Veneto, 58, 31012 Cappella Maggiore (TV), Italy, \\ gabriele.gava@gmail.com
}

\begin{abstract}
The aim of this paper is to determine whether Charles S. Peirce's direct criticisms of the transcendental method in philosophy are effective. I will present two different views on transcendental arguments by introducing two ways of accounting for Kant's transcendental project. We will see that Peirce's criticisms are directed against a picture of transcendental philosophy which is in line with what I will call the justificatory account of Kant. Since this view is totally in contrast to what I will call the alternative account, Peirce's criticisms of the former cannot be considered a refutation of the latter. As far as Peirce's criticisms attack only justificatory accounts of transcendental philosophy, they are not in conflict with transcendental readings of his philosophy along the lines of the alternative account.
\end{abstract}

\section{Introduction}

The aim of this paper is to determine whether Peirce's direct criticisms of the transcendental method in philosophy can be used to assess if he was a transcendental philosopher or not. In Peirce scholarship very different views about the transcendental character of his thought have been proposed. On the one hand, Karl Otto Apel is certainly the most famous advocate of a transcendental interpretation, ${ }^{1}$ but he is not the only one. ${ }^{2}$ On the other hand, today's predominant account sees Peirce as a philosopher totally inimical to transcendental standpoints. ${ }^{3}$ Scholars endorsing this latter view often refer to Peirce's direct criticisms of the transcendental method to sustain their theses.

In fact, throughout his philosophical career, Peirce directed various criticisms against what he calls the transcendental method in philosophy. This surely provides strong evidence that he was unsympathetic to transcendental standpoints. However, it is insufficient simply to note that Peirce makes criticisms, without understanding their basis. In order to use Peirce's own criticisms against transcendental projects one would have to determine if

1 Apel 1981.

2 See, for example, Christensen 1994; Abrams 2004; Pihlström 2003; Cooke 2006, chap. 7.

3 See, for example, Oehler 1987 and 1995; Misak 1994; Hookway 2000, chap. 7; Short 2000; Midtgarden 2007.

Archiv f. Gesch. d. Philosophie 93. Bd., S. 195-221

DOI 10.1515/AGPH.2011.009

(C) Walter de Gruyter 2011

ISSN 0003-9101 
the picture of the transcendental method on which those criticisms are based is actually correct, or is capable of addressing any possible transcendental inquiry.

In my view, the debate on whether Peirce was a transcendental philosopher or not has been carried on without a clear understanding of what the word 'transcendental' can mean. Thus, this paper will first contrast two very different ways of accounting for transcendental enterprises. In order to develop this distinction, I will present two ways of interpreting Kant's transcendental project. The former, which I will call the justificatory account of Kant, sees him as directly concerned with sceptical challenges and is the view often endorsed in the contemporary debate on 'transcendental arguments'. The latter, which I will call the alternative account, considers Kant as involved in an explanatory, rather than justificatory, inquiry. These two contrasting ways of interpreting Kant have already been recognized by other commentators. ${ }^{4}$ However, they have never been used to ascertain how much of a transcendental philosopher Peirce appears to be. So, by introducing the distinction between a justificatory and an alternative account of Kant in this context, we can obtain new insights on two main points: one concerns the relationships of non-justificatory readings of Kant with pragmatic themes, and the other, which is the main focus of this article, relates to the possible new lines of inquiry that this non-justificatory reading gives us with reference to Peirce's philosophy. In fact, even those works which try to advance a transcendental interpretation of Peirce seldom clarify what they mean by the word 'transcendental' and the associated interpretation.

As I have already stressed, the chief task of this study is to establish if Peirce's direct criticisms of transcendental enterprises in general, and of Kant in particular, can actually be used to demonstrate his distance from any transcendental project. In this respect, a detailed study of the possible ways of accounting for transcendental philosophy is strongly needed in the literature on Peirce. No inquiry into the relationship of Peirce's work with transcendental philosophy could begin without first ascertaining if Peirce's direct criticisms are exhaustive. We will see that Peirce's criticisms are directed against a picture of transcendental philosophy which is in line with what I have called the justificatory account of Kant. Since, as we will see, this view is totally in contrast to the alternative account, Peirce's criticisms of the former cannot be considered a refutation of the latter.

I will begin the statement of my thesis by discussing the justificatory account of Kant. Peter Strawson's interpretation of Kant will be used to clarify this understanding. Then, I will show that Peirce's criticisms of Kant and transcendental methods share many characteristics with this view. To finish, I will propose an alternative view of Kant's project which is totally in

4 Allison 1983; Bird 2006; Collins 1999. 
contrast to the justificatory account and so leaves open the possibility of finding in Peirce a kind of transcendental inquiry which does not conflict with his criticisms of transcendentalism.

\section{The justificatory account of Kant and transcendental philosophy}

Since the appearance of the first edition of the Critique of Pure Reason, Kant's work has faced a series of interpretations and criticisms which have attributed to him an attempt to resolve problems that were proper for his predecessors. More precisely, these interpretations attribute to Kant the Cartesian Idealist problem concerning the veracity of our knowledge of the external world. Traditional rationalists and empiricists all worked within that framework, the former stressing that reason alone can provide knowledge of that external world, the latter claiming that all knowledge must be mediated by the senses. In both cases, the problem arises whether the means we have of developing knowledge are fit for representing an independent reality.

Interpreted from this perspective, Kant's problem becomes that of determining whether our knowledge of an external world can be considered legitimate. His distinctive way of dealing with this question lies in the claim that we do not need to gain knowledge of a totally independent reality in order to secure our truth claims. On the contrary, knowledge is limited to the appearances of objects within us, and these appearances can guarantee objectivity and truth, insofar as our mental constitution provides us with some necessary rules that compel those appearances to conform to a particular structure. In other words, following this account of Kant's project, we would not have to worry about our knowledge of an external world insofar as that world would be actually a product of our mind.

Criticisms of transcendental approaches from a Peircean perspective often share some implications of this interpretation. Thus, for our purposes, it is important to focus on three peculiar characteristics of this reading:

(a) Kant's philosophy is seen as an anti-sceptical enterprise, aiming at securing our knowledge of the external world against any doubt about its truth;

(b) Kant is supposed to endorse a mentalistic framework in which philosophy has to justify the appropriateness of mental representations to represent outer reality. In this endeavour, propositions about the self and its inner states are considered privileged departing points in philosophical analysis; ${ }^{5}$

5 A metaphysical view on the subject which considers it as a kind of substance is often, but not necessarily, associated with this philosophical perspective. As we will see, Strawson attributes this metaphysical view on the subject to Kant's 'metaphysics of 
(c) Kant's deductions are understood as aiming at providing a rigidly deductive argument able to secure objectivity, departing from self-sustaining a priori propositions.

In what follows, I will analyze Peter Strawson's interpretation of Kant in order to see how these characteristics are developed by him. In this respect his work is particularly interesting, insofar as he not only proposed a quite representative interpretation, but also influenced the contemporary debate on transcendental arguments, and, consequently, a very widespread opinion on transcendental philosophy in general.

\section{Kant as an anti-sceptical philosopher}

It was Kant himself who said that Hume awakened him from his dogmatic slumber. ${ }^{6}$ Accordingly, Kant can be read as trying to find a way to secure causality from Hume's sceptical attack, a way which takes into consideration Hume's criticism of the rationalist standpoint. ${ }^{7}$ Moreover, it is indubitable that Kant proposed a rejection of scepticism about the external world in his Refutation of Idealism (KrV, B 274-279). Focusing on these two points of Kant's work it is easy to see him continuing the work of his predecessors. As a result, Kant seems to deal first of all with an anti-sceptical enterprise, the one of trying to secure some ordinary and scientific beliefs, such as the belief in external objects or the belief in the law of causality, against any possible doubt.

It was in this light that Peter Strawson interpreted and revitalized Kant in his 1966 book The Bounds of Sense. ${ }^{8}$ His project was that of disentangling what he considered a valid argument in Kant's first Critique from the metaphysical and psychological doctrines which he thought the German thinker had muddled up with this valid argument. He then distinguished a legitimate descriptive metaphysics, which describes necessary relationships in our conceptual framework and is linked to anti-sceptical conclusions via a

transcendental idealism', but rejects it as an essential part of the analytic argument that he wants to disentangle from the first Critique. However, Strawson's analytic argument still treats the self-referring capacity of the subject as a privileged departing point in philosophical analysis, insofar as it is not doubted by the sceptic.

6 See Prol., 260. In a letter to Garve from 1798, Kant stresses that the antinomies woke him from the slumber of dogmatic metaphysics (PC, 252). This account of his critical turn is more in line with our interpretation.

7 Especially in the Second Analogy (KrV, A 189-211/B 232-256) of the first Critique, Kant advanced an answer to Hume's doubt on causality. However, this is not his first problem, and his way of answering Hume is to show that it is his very way of setting the problem that leads to sceptical conclusions. From his transcendental perspective, Kant thinks the problem does not arise at all. So it cannot be considered his first concern.

8 Strawson 1966. 
transcendental argument, and an illegitimate metaphysics of transcendental idealism, which proposes problematic reflections upon our cognitive constitution in order to found objectivity upon a transcendent metaphysics of the self. ${ }^{9}$

Leaving aside the possibility of disentangling an analytic argument from the rest of Kant's system and the question of the correctness of Strawson's rendering of transcendental idealism, ${ }^{10} \mathrm{I}$ wish, rather, to focus on the aims and presuppositions which Strawson attributed to both the legitimate metaphysics of experience and the metaphysics of transcendental idealism. The first of these common aims is an anti-sceptical outcome. Following characteristic (a) of the justificatory interpretations of Kant previously introduced, Strawson thought that the first concern of the German thinker was that of securing the objective value of our knowledge. In this respect, he paradigmatically read the Transcendental Deduction in the light of the Refutation of Idealism, that is, the section in which Kant was directly concerned with an answer to the sceptic. ${ }^{11}$ Thus, the purpose of the Transcendental Deduction, ${ }^{12}$ together with the Refutation of Idealism, became that of proving that the objects we perceive have "a permanence independent of our perception of them"13 and thus are "numerically the same in different perceptual situations". ${ }^{14}$ If the permanence of objects is one of the things that Kant's first Critique aimed to prove, this was also true for causality, or so at least Strawson thought. ${ }^{15}$ So, Kant's first aim was that of warranting knowledge in general, and some of its particular concepts in particular.

A project like that, that is, one being undertaken to prove the existence of objects by means of a compelling argument, must endorse a very strong presupposition about mental ideas and the objective world. Accordingly,

9 Accordingly, concerning transcendental idealism, Strawson asserted: "Though it is difficult to disentangle its doctrines from the analytical argument of Kant's positive metaphysics of experience, yet, when the disentangling operation has been carried out, it is remarkable how little those doctrines appear to have distorted the argument" $(1966,42)$.

10 For a criticism of Strawson's views on transcendental idealism, see Allison 1983.

11 In reference to the argument proposed in the Transcendental Deduction, Strawson states: "The force of these contentions is by no means immediately obvious. It becomes somewhat clearer when we turn to certain sections of the Principles, which are supposed to contain a more detailed working out of the implications of the Deduction; notably, to the argument called the Refutation of Idealism and the arguments of the Analogies" (1966, 27).

12 "Kant's sense of the need for a Transcendental Deduction not merely as an explanation but as a proof - a need he himself clearly feels, but never very clearly explains accords very satisfactorily with our suspended analytical hopes. A major part of the role of the Deduction will be to establish that experience necessarily involves knowledge of objects, in the weighty sense" (Strawson 1966, 88).

13 Strawson 1966, 126.

14 Strawson 1966, 126.

15 See Strawson 1966, 133-146. 
Strawson attributes to Kant's own position the mentalistic standpoint indicated in (b). Kant's inquiry appears to be undertaken by a subjective mind inquiring into the validity of its own representations. According to this philosophical standpoint, the only certainty we have is the fact of having mental representations, but the relationship of these with the external objects they represent is problematic. Thus, representations about the self and its inner states are considered privileged departing points in philosophical analysis in the attempt of providing a vindication of our knowledge. Kant's perspective appears thus to be bound up with a mentalistic point of view, in which we would have to prove the existence of outer objects through an analysis which goes beyond our representations. Kant's move in this respect is not very different from Berkeley's. In fact, thinks Strawson, he tried to justify objectivity by stressing that appearances are nothing but mental ideas, that the entire world is nothing but a product of the mind. ${ }^{16}$

The doctrine that the material and the mental constituents of the natural world are alike only appearances turns out, in the end, to bear with unequal weight on bodies and states of consciousness. Kant, as transcendental idealist, is closer to Berkeley than he acknowledges. ${ }^{17}$

Thus, for Strawson, Kant's transcendental idealism involves a metaphysical view on mind which stresses that objects in general are only its phenomenal products. Strawson, unsurprisingly, rejected this Kantian move. That is, in the valid analytical argument that he claimed to separate from the rest of Kant's position, he did not take this idealistic step. For Strawson we do not need to stress that the world is a product of our representation in order to warrant the reality of objects. This version of idealism is just that part of Kant's philosophy that Strawson wanted to avoid. However, even if Strawson rejected this form of idealism he attributed to Kant, he still considered the justification of our representations of outer objects as an essential philosophical problem. Accordingly, he used propositions concerning inner states as privileged departing points in the attempt of connecting mental representations to outer objects. He thus maintained the mentalistic viewpoint which interrogates itself on the validity of representations to represent an independent reality. In fact, a position that aims to prove the existence of

16 A good exemplification of this reading of Kant is found in Barry Stroud, who challenges Kant's perspective by raising the question: "what it means, for example, to say that the sun and the planets, and the mountains and continents which have been on this particular planet so much longer than we have, are nevertheless in some sense dependent on the possibility of human (or any other) thought and experience" (Stroud 1994, 235). The fact that Stroud thinks it is problematic to maintain, from a Kantian perspective, the existence of objects before human beings appeared shows that he interprets Kant's transcendental idealism as stressing that the world is actually a product of the human mind and is no more than a set of ideas.

17 Strawson 1966, $21 \mathrm{f}$. 
outer objects and their enduring subsistence while unperceived cannot but endorse a perspective which considers representations as the only certainty and which regards the relationship of those representations to outer objects as being problematic. Moreover, as far as Strawson needs to use as premises only propositions that can be recognized by the sceptic, he is obliged to attribute to inner representations a privileged status.

If, according to Strawson, Kant's purpose is that of justifying our knowledge of objects from a mentalistic perspective, a very stringent argument would be required to accomplish that aim. Thus, if, following (a) and (b), Kant endorsed an anti-sceptical enterprise focused on our inner representations, following (c), he needed to provide a strong deductive argument showing that the existence of objects is required by the very possibility of the self-ascription of experiences. Unsurprisingly, Strawson reads Kant's Transcendental Deduction in this way.

The structure of the required argument is Cartesian in essence. It must rest on a self-sustaining proposition and deduce the necessity of the required conclusion showing the implication of the latter in the former. The self-sustaining proposition might be a proposition whose negation would imply a performative contradiction for anyone trying to negate the required conclusion. This way of arguing is evidently Cartesian. It recalls the way in which Descartes showed the invulnerability of belief in the Ego, arguing that anybody who doubted its existence would actually fall into contradiction with the very possibility of doubting. Barry Stroud exemplifies very well this way of considering transcendental arguments when he says:

If there were things that were necessary conditions of thought in that sense we would see that they must or simply have to be true in pretty much the same way in which we recognize, for example, that someone who says that he is speaking must be saying something true. It is not possible for me to speak truly while saying that I am not speaking. Not because it is not possible for what I am then saying to be true. What I am saying is that I am not speaking, and it is possible for that to be true; I am often not speaking. But it is not possible for it to be true when I am speaking, and so not even when I am saying that I am not speaking. Similarly with such self-guaranteeing thoughts as 'I am thinking' or even 'There is thought'. ${ }^{18}$

18 Stroud 1994, 232f. This self-guaranteeing premise resembles G. E. Moore's pragmatic paradoxes, according to which it would be absurd for anybody to say 'it's raining but I don't believe it is'. Graham Bird stresses that the structure of the premises of a transcendental anti-sceptical argument is really more complex than this example allows (2006, 246-248), both in its original Kantian form and in its contemporary interpretations. However, I think the contemporary attempts work similarly when they address the impossibility for the sceptic to deny the possibility of referring to his inner experience. What renders transcendental arguments really more complex is the attempt to connect the possibility of self-reference, granted by the self-sustaining premise, to the existence, or the belief in the existence, of an external world. 
After this self-guaranteeing or self-sustaining proposition has been accepted, the argument must show that the aimed conclusion, for example the existence of objects, is necessarily implied in that self-sustaining proposition. So, let us say that the proposition 'I can ascribe thoughts and experiences to myself' is a self-sustaining proposition of the kind just presented. If, for example, the proposition asserting the existence of objects were necessarily implied in that self-sustaining proposition, one would be able to prove the truth of the former, since the very possibility of doubting it would imply the self-ascription of thoughts and, consequently, the existence of objects. Recapitulating, the structure works as follows: firstly, a self-sustaining proposition is proved to be necessary for the same possibility of doubting the proposition in question. Secondly, the proposition in question is shown to be implied in the same possibility of the self-sustaining proposition. Consequently, the proposition in question is shown to be necessarily implied in the same possibility of questioning it. This is the way in which Kant's transcendental line of reasoning is supposed to work according to Stroud. It is often considered the model for every kind of transcendental enterprise. If we come back to Strawson's interpretation, it is easy to show that it is a view of this kind. Accordingly, he presented Kant's argument as follows:

The operation is very simple. For the necessity of saving the recognitional component in an experience from absorption into its sensible accusative (and thereby saving the status of the experience as experience) is simply identical with the necessity of providing room, in experience, for the thought of experience itself; and it is just this necessity which calls directly for the distinction between how things are and how they are experienced as being and hence for the employment, in judgments of experience (though not in every such judgments) of concepts of the objective. ${ }^{19}$

The recognitional component of experience is equivalent to the possibility of self-consciousness. Thus, Strawson says, the possibility of self-consciousness, that is, the possibility of ascribing thoughts and experiences to the same self, is necessarily implied in the same concept of experience. As such, self-consciousness functions like one of those self-sustaining propositions indicated previously. It would be self-contradictory to doubt the possibility of this self-consciousness, insofar as the position of that same doubt would imply self-consciousness. Accordingly, since the same concept of self-consciousness involves the concept of the objective world, it is also self-contradictory to doubt the latter. This seems to be how Strawson summarizes Kant's argumentative procedure.

Strawson's rendering of Kant's project well exemplifies what we have called the justificatory interpretation of Kant and transcendental philosophy. Thus, Strawson's position on Kant and transcendental arguments endorses what we indicated as characteristics (a), (b), and (c) of the justifi-

19 Strawson 1966, $110 \mathrm{f}$. 
catory interpretation of Kant. His criticism of Kant is not directed in any way against any one of these points. On the contrary, he refers to them as strong reasons for revaluating what he called the analytical argument of the Critique. In this way, due even to the influence of Strawson's work outside Kant's scholarship, these characteristics became the features which had to distinguish any transcendental enterprise, be they directly Kantian or not.

It is my view that this way of accounting for Kant and the transcendental method is shared by most of the critics of transcendental interpretations of Peirce. However, this is not all. It is Peirce himself who challenges Kant's philosophy for the same features listed above, that is (a), (b) and (c). It is to these Peircean criticisms that we now turn.

\section{Peirce's criticism of the transcendental method}

It is often stressed that Peirce was strongly Kantian when young and then moved progressively away from this heritage. ${ }^{20}$ If he was a Kantian or not, ${ }^{21}$ it is surely true that he began to attack the transcendental method in philosophy quite early on in his career. I wish to analyze the criticisms he expressed against transcendental methods and establish if he proposed a justificatory interpretation or not. Peirce's 1867 paper "A New List of Categories" (W 2, 49-59) is normally considered the culmination of his early re-elaboration of Kant's deduction of the categories. The Kantian value of this text notwithstanding, Peirce directed a strong criticism against transcendental philosophy already in 1861, and Kant was surely one of his first targets:

When the view that metaphysics is the study of the human consciousness is carried out in a one-sided way, in forgetfulness that it is as truly Philosophy and also the Analysis of Conceptions, it produces Transcendentalism (better named Criticism), which is the system of investigation which thinks necessary to prove that the normal representations of truth within us are really correct $(\mathrm{W} 1,72)$.

20 This is, for example, the view of Thomas Short, who considers the derivation of the categories in the "New List" strongly Kantian, while deeming the later developments quite contrary to this project. He writes: "I suggest, however, that Peirce later abandoned the argument of the piece [sc. "A New List of Categories"; G.G.]: beginning in the 1890 s, he restated the categories on an entirely different basis and explicitly forswore any a priori demonstration of their necessity. Around 1894 he wrote that 'each category has to justify itself by an inductive examination which will result in assigning to it only a limited and approximate validity" (Short 2007, 31). Another example of this view, from a very different perspective, is found in Esposito 1980.

${ }^{21}$ In 1905 Peirce stressed that a Kantian had just to abjure the doctrine of the thingin-itself to become a critical common-sensist (EP 2, 353f.). This is just to show that passages in which Peirce expresses either his closeness or his distance to Kant can be equally found even after 1900 . 
It is not easy to grasp the thoughts entailed in this passage. What Peirce here calls 'Criticism' seems to be really different from Kant's use of the term and in general Peirce's terminology is not easily associable to a transcendental perspective. One gets the impression that Peirce is more concerned with the construction of a philosophical adversary than with an interpretation of Kant and transcendental philosophy. Keeping in mind these difficulties we need now to interpret this passage in order to delve into Peirce's account of 'transcendentalism'. Peirce thought transcendentalism to be invalid due to an unavoidable circularity. The very warrant that transcendentalism should provide for our normal representations would be needed also for transcendentalism itself, the latter thus resulting in being unwarranted..$^{22}$ Leaving aside Peirce's reasons for criticizing transcendental philosophy, let us concentrate on his characterization of it. The paper from which the previous passage is extracted is entitled "A Treatise on Metaphysics" (W 1, 57-84). At that time, Peirce challenged transcendental philosophy for its way of addressing metaphysical questions.

In the last sentence of the quote there are some hints that Peirce endorsed a justificatory interpretation of Kant and transcendental philosophy. Accordingly, he stresses that transcendental philosophy "is the system of investigation which thinks necessary to prove that the normal representations of truth within us are really correct". The aim of proving the correctness of our representations seems to imply the attempt of offering a justification of our knowledge. This would entail anti-sceptical consequences as justificatory accounts claim for Kant's method. But this is not all; the representations that transcendental philosophy aims to justify are "within us". Philosophy should prove that mental representations are fit to represent outer reality. This appears to imply a perspective on philosophy which we have called mentalistic. The passage does not tell anything more on this point. It is impossible to get whether Peirce attributed to Kant any metaphysical view on the self or an idealistic standpoint on perception. However, it seems correct to consider Peirce's grasp on Kant mentalistic, since he thought that Kant was still concerned with the problem of justifying the appropriateness of mental representations to represent outer reality.

This is confirmed by Peirce's attacks on the Kantian concept of a thing in itself. In Kantian scholarship there are two ways of considering the Kantian distinction between appearances and things in themselves: these are generally referred to as the 'two worlds' and the 'two aspects' interpretations. According to the two worlds view, things in themselves are outer objects

22 "Psychological transcendentalism says that the results of metaphysics are worthless, unless the study of consciousness produces a warrant for the authority of consciousness. But the authority of consciousness must be valid within consciousness or else no science, not even psychological transcendentalism, is valid" (W 1, 73). On this topic, see Murphey 1961, 26. 
that causally affect the subject producing phenomenal appearances. On the contrary, according to the two aspects view, appearances and things in themselves are two different ways of considering the same thing, which can be regarded in its relationship with the subject or not. ${ }^{23}$ Generally, those who attribute to Kant a mentalistic framework consider him as proposing a two worlds view. In fact, Kant is seen as attempting to justify the appropriateness of our representations to represent outer reality. His claim that we can obtain this justification only if we limit ourselves to appearances does not affect the basic causal view on the relationship between appearances and things in themselves that lies behind the need to justify the appropriateness of representations to represent outer reality. Peirce attacks Kant's concept of a thing in itself in various papers, attributing to him what we have called the two worlds view. Thus, he considers the thing in itself as the incognizable first cause of perception and he regards Kant as arguing that we cannot justify our knowledge with respect to this incognizable cause, but only to its mental representation. ${ }^{24}$ This view on Kant's concept of a thing in itself gives us another important indication that Peirce attributed to Kant a mentalistic perspective in philosophy.

From this initial scrutiny of Peirce's early writings, it appears that the young Peirce endorsed points (a) and (b) of our characterization of the justificatory interpretation of Kant. For him, Kant aimed at a justification of our common beliefs about the world and he did that on the basis of a mentalistic perspective.

Thus, in 1861, Peirce seems to attribute to Kant and transcendental philosophy just points (a) and (b). This could be a consequence of the metaphysical interest of his analysis at that time. In fact, characteristic (c) claims a peculiar way of arguing is necessary for transcendental philosophy and the focus of Peirce was not methodological in his "Treatise". However, if we move on sixteen years, when his famous paper "The Fixation of Belief" was published, something like characteristic (c) seems to be attributed also to transcendental methods. Unlike his 1861 work, the aim of "The Fixation" is immediately methodological. As the title suggests, it aims to determine what is the best method for fixing our beliefs. In this context Peirce presents the a priori method as one that determines truth by indicating what is "agreeable to reason" (W 3, 252). Its rationale consists in considering as unquestionable truths only those propositions that suggest themselves by reason alone. Thus the a priori method stands out because it ignores any question of fact, ${ }^{25}$ and because it proceeds according to what seems to be a purely logical and deductive methodology.

${ }^{23}$ Henry Allison (1983) is the most famous advocate of this interpretation.

24 See W 2, $238 \mathrm{f}$.

25 Peirce presented the history of metaphysical philosophy as the best example of this way of arguing. He then states: "Systems of this sort have not usually rested upon any observed facts, at least not in any great degree" (W 3, 252). 
This is Peirce's view on the a priori method in philosophy. It is quite easy to show that he attributed it also to Kant and transcendental philosophy in general. In fact, in a 1893 revision of "The Fixation" for a publication in a book, Peirce analyzed some philosophical views in order to show their affiliation to a priori ways of arguing. Among those, there was Kant, whose position, Peirce stressed, was intended to warrant our common beliefs by an a priori argument.

I might go through the Critic of the Pure Reason, section by section, and show that the thought throughout is precisely of this character. He [sc. Kant; G.G.] everywhere shows that ordinary objects, such as trees and gold-pieces, involve elements not contained in the first presentations of sense. But we cannot persuade ourselves to give up the reality of trees and gold-pieces. There is a general inward insistence upon them, and that is the warrant for swallowing the entire bolus of general belief about them (CP 5, 382 n.).

So, Kant's first Critique has a justificatory purpose according to characteristic (a) of our description of justificatory accounts of transcendental philosophy. But what is more important here is that Peirce stresses the point that to accomplish this purpose Kant endorsed Peirce's own rendering of the a priori method; a method that associates Kant with Descartes and is characterized by its claiming to offer purely rational arguments not based in any way on experience. Even if Peirce does not describe the a priori method exactly as we presented the argumentative procedure of justificatory transcendental enterprises, that is, as a purely deductive procedure based on some self-sustaining propositions, it seems that his view is quite similar to justificatory accounts such as Strawson's. In fact, a purely rational procedure, totally detached from experience, is intended to guarantee a set of propositions. This rational procedure, in order to be compelling, must rest on premises that cannot be rationally refuted. This is the common idea that lies behind both Strawson's and Peirce's accounts of transcendental and a priori methods, respectively.

Thus, considering together these two texts which Peirce wrote in very different periods of his theoretical career, we have various elements to maintain that Peirce attributed to Kant and transcendental philosophy characteristics (a), (b) and (c) of our rendering of the justificatory account of the transcendental method. To be fair, Peirce is not so consistent concerning characteristic (b). Sometimes, he even uses Kant as a contrast to idealistic approaches to perception which he thinks are closely connected to a mentalistic perspective on philosophy. I would like just to mention one example: the doctrine of immediate perception. In contrast to, for instance, the view of the British empiricists, Peirce held that we do not infer the existence of outer objects by assembling inner sensations. On the contrary, outer objects are directly perceived as such. Kant, as well as Thomas Reid, is a recurrent reference when Peirce introduces this view: 
That, of course, is the doctrine of Immediate Perception which is upheld by Reid, Kant, and all dualists who understand the true nature of dualism, and the denial of which led Cartesians to the utterly absurd theory of divine assistance upon which the preestablished harmony of Leibniz is but a slight improvement. Every philosopher who denies the doctrine of Immediate Perception, - including idealists of every stripe, - by that denial cuts off all possibility of ever cognizing a relation. Nor he better his position by declaring that all relations are illusive appearances, since it is not merely true knowledge of them that he has cut off but every mode of cognitive representation of them (EP 2, 155).

As far as outer objects are directly perceived, it seems that, for Peirce, the doctrine of immediate perception renders meaningless the question about their existence. Descartes, Leibniz and the British empiricists ${ }^{26}$ all seem guilty of the idealistic assumption that generates this question. Only when endorsing that assumption does one need to consider the problem of the relation between the subjective idea and the objective thing. So, in attributing to Kant the doctrine of immediate perception, Peirce uses him as an example in contrast to an idealistic view on perception that is often connected to the mentalistic framework on which justificatory accounts normally insist. ${ }^{27}$

This generates an apparent contradiction in Peirce's interpretation of Kant. We saw that, according to characteristics (a) and (b) of the justificatory interpretation of Kant, Peirce stressed that the German's purpose was that of guaranteeing the correctness of our ideas in order to represent real outer objects. However, in the fragment we just quoted, Peirce held that the doctrine of immediate perception overturns the same possibility of seriously taking into consideration a question like that. So, if Peirce, according to (a) and (b), held that Kant's project was justificatory in purpose and mentalistic in form, how could he also stress that the German correctly proposed the doctrine of immediate perception?28 I think that the correct way to answer this question is by separating Peirce's view on Kant's transcen-

${ }^{26}$ In the text just quoted, Berkeley seems to be the polemical target of the last sentence.

27 Strawson does not endorse this idealistic view on perception. On the contrary, the analytic argument he disentangles from the Critique intends to show how representations of inner states presuppose the existence of outer objects. Outer objects have thus priority with respect to inner states. However, even if Strawson rejects this idealistic position on perception, he still considers the justification of mental representations of outer objects as a central philosophical problem and thus he treats inner representations as privileged departing points in philosophical arguments. The priority of objects over representations can thus be only a result of his line of reasoning, but not a methodological assumption.

${ }^{28}$ It cannot be stressed that these contrasting positions are held in very different periods. In fact Peirce used a Kantian argument to contrast Cartesian subjectivism already in his 1868 paper "Question Concerning Certain Faculties Claimed for Man" (W 2, 205-207) and Peirce accuses Kant of endorsing a mentalistic viewpoint also in later years. 
dental philosophy from his general view on Kant. So, if, for Peirce, some of Kant's teaching was worth retaining, ${ }^{29}$ this was not part of what was involved in his transcendental perspective. It seems that Kant's transcendental philosophy is guilty of (a), (b) and (c), thus involving a mentalistic framework. However, there are elements of Kant's teaching that are separable from this framework and so are also independent from transcendental approaches. The doctrine of immediate perception is one of these. Of course, that involved ascribing to Kant a pretty serious inconsistency. This appears to be the view that lies behind Peirce's contrasting assertions concerning (b). Since our non-justificatory account of the transcendental method will not only cohere with the doctrine of immediate perception, but also require it, Peirce's endorsement of this latter doctrine will not be a reason for conclusively accepting his rejection of transcendental philosophy. Our account of the transcendental method will not just be adjusted in order to make it consistent with the doctrine of immediate perception. On the contrary, immediate perception will be the only view that will make it possible to set a transcendental problem in that sense.

However, our purpose here is not to present our view of transcendental philosophy, but to illustrate Peirce's own interpretation of Kant. From what we said, it is clear that Peirce interpreted Kant's transcendental project along the lines of the justificatory account presented in section 2. Beside this critical standpoint on the German's perspective, Peirce held a positive view on some of his teachings, provided that these were detached from the main structure of Kant's system.

Thus, Peirce, at least until 1877, was really critical of transcendental philosophy exactly for the same features which characterize justificatory accounts. We have now to determine if Peirce's interpretation of Kant's transcendental method remained the same over the years. If considering "A Treatise on Metaphysics" together with "The Fixation of Belief" we find Peirce holding characteristics (a), (b) and (c) of the justificatory account of Kant, it is still an open question if that was his view even later on. If we consider a passage in the "Minute Logic", written in 1902, it seems that this question can be answered in the affirmative:

I may as well notice here a style of reasoning much used for the support of instinctive beliefs. I mean the transcendental method. [...] The method was the invention of Kant, and in his hands it consists in showing, by some ingenious argument [...] that the logical analysis of the process which the mind must go through shows that the proposition which is to be defended is involved in the a priori conditions of the possibility of practical everyday experience (CP 2, 31).

${ }^{29}$ Kant's doctrine of schematism was another teaching that Peirce considered very important (W 5, 258f.). In fact, Peirce thought his diagrammatic logic to be in continuity with Kant's schemata (NEM 4, 318). 
This fragment is not immediately clear. However, Peirce states straight away that the transcendental method aims at supporting our instinctive beliefs. What is not immediately clear is the way in which it tries to do so. Peirce stresses that the object of study for transcendental approaches is "the process which the mind must go through". This seems to involve a psychological perspective focused on inner states, that is, a mentalistic standpoint. Thus far, the passage confirms that Kant aimed to provide a justification of our knowledge privileging inner mental states in his analysis. But what was the method he used to accomplish his justificatory enterprise? Peirce says that Kant claimed to prove, by logical analysis, that "the proposition which is to be defended is involved in the a priori conditions of the possibility of practical everyday experience". This means that, for Peirce, Kant attempted to establish a necessary connection between some indisputable propositions concerning the mental process by which we obtain experience and the ordinary propositions that transcendental analysis aims to secure.

Consequently, following this 1902 statement, Peirce's interpretation of Kant remained the same concerning the characteristics that are relevant for our purposes. The standpoint from which Peirce launched his criticism has changed in the different texts here considered. However, the reasons why he criticized Kant and transcendental philosophers remained unaltered. For him, Kant was a philosopher aiming at an anti-sceptical result; he endorsed a mentalistic perspective privileging inner states, and claiming to offer a self-sustaining rational argument. That was the interpretation of Kant and the transcendental method on which Peirce based his evaluations of the success of Kant's project. Moreover, it was also the basis on which Peirce judged upon the transcendental nature of his own system. In fact, Peirce, following his interpretation of Kant, had an idea of what it would have meant for him to argue transcendentally within his own perspective. That idea was a further reason for him to reject transcendental approaches. However, if the interpretation on which Peirce based both his criticism of Kant and his prohibition to construe his own system transcendentally were faulty, his rejection could not be considered exhaustive.

\section{Peirce's portrayal of a possible transcendental way of arguing in his own system}

According to his interpretation of Kant, for Peirce, to argue transcendentally would have meant to develop a purely deductive line of reasoning based on self-sustaining propositions. In addition, this deductive strategy would have had to be able to derive propositions about experience from propositions about our mental states; this derivative step being the only possible procedure for accomplishing the guaranteeing aim of transcendental arguments. Thus, besides criticizing this kind of procedure in Kant, 
Peirce also had an idea of what he would have had to do to develop a transcendental argument from his own perspective. If the argumentative procedure of transcendental inquiries lay in securing positive truths about the world and experience from some a priori self-sustaining propositions concerning our inner ideas, Peirce thought that to undertake a strategy of this kind he would equally have had to obtain legitimate propositions about the external world just on the basis of certainly valid a priori truths. In his system that would have been equal to deriving propositions ascribable to the positive sciences, that is, to philosophy and the special sciences, from propositions belonging to sciences totally independent of experience. As we will see, the result of this self-interpretation of Peirce is very far away from anything we could find in Kant. However, it will confirm that Peirce's interpretation of Kant and the transcendental method is of the justificatory type.

In Peirce's classification of the sciences, the positive sciences are those sciences that teach something about the actual existing world. As such, they all rest, even though in various degrees, on observations. They are divided into philosophy and the special sciences. Philosophy is characterized by not resting on particular observations, but just on commonly recognizable beliefs. The only science that is not committed to the discovery of truths about the actual world is mathematics. Even if, for Peirce, it also rests on observations, insofar as it needs diagrams for its development, it is nonetheless a priori, due to its investigating what is possible and not what is actual. Consequently, if transcendental arguments need to derive truths about the external world from self-sustaining truths regarding our mental states, it means that Peirce, in order to develop his philosophy in that way, needed to derive positive knowledge from an application of mathematical considerations to mental issues, ${ }^{30}$ or at least he thought so.

Accordingly, in a manuscript written in 1905, Peirce developed an argument of this kind, stressing however that it was insufficient for proving anything. The first step Peirce had to take was the identification of a selfsustaining truth on which to base the argument. That had to be a truth directly involved in the idea of a mental phenomenon, or of a 'phaneron' in Peirce's words:

Unless the Phaneron were to consist entirely of elements altogether uncombined mentally, in which case we should have no idea of a Phaneron (since this, if we have the idea, is an idea combining all the rest), which is as much as to say that there would be no Phaneron, its esse being percipi if any is so; or unless the Phaneron where itself our sole idea, and where utterly indecomposable, when there could be no such thing as an interrogation and no such thing as a judgment [...], it follows that if there is any Phaneron [...], or even if we ask whether there be or not, there must be an idea of combination. [...] Therefore, if there is a Phaneron, the idea of combination is an indecomposable element of it (EP 2, 363f.).

30 The kind of positive knowledge that is at issue here is obviously philosophical, due to the general character of the propositions that have to be derived. 
Thus, combination is an unavoidable element in order to account for the phaneron, insofar as the latter would be unintelligible without a reference to the former. Moreover, the same questioning of the phaneron involves the idea of combination, so that doubting its essentiality would produce a performative contradiction. ${ }^{31}$ That is to say, the concept of combination possesses the characteristics that justificatory accounts of the transcendental method claim for the premises on which their argument must rest.

After having established the legitimacy of the concept of combination, Peirce, by applying the logic of relatives, argued that his three categories necessarily follow that concept. So, he first stressed that combination is essentially triadic, ${ }^{32}$ and then argued that dyadic and monadic relations are necessarily involved in it. ${ }^{33}$ Through the logic of relatives, which, for Peirce, is strongly based on mathematical considerations, the categories are proved to be involved in the self-sustaining proposition introduced previously. Hence, Peirce seems to propose a line of reasoning very similar to what he considered to be the strategy of transcendental methods: an a priori deductive argument based on a supposedly indubitable proposition. ${ }^{34}$

However, Peirce thought that this argument could not really prove anything by itself. If transcendental arguments are intended to guarantee answers to questions concerning factual experience by means of a purely a priori line of reasoning, Peirce thought that the step from the purely logical necessity of the argument to its factual necessity was not actually warranted. A step of this kind would fall into the common mistake of every a priori method, that is that of considering absolutely necessary what is actually just familiar from our historical perspective. Thus, mathematical a priori considerations do not warrant any step from purely logical possibility to positive knowledge of actual facts. They are of value in the analyses of

31 Accordingly, in the quote Peirce said "if there is any Phaneron [...], or even if we ask whether there be or not [my italics; G.G.], there must be an idea of combination".

32 "This Idea [sc. Combination; G.G.] is a triad; for it involves the ideas of a whole and of two parts" (EP 2, 364).

33 "Suppose then a Triad to be in the Phaneron. It connects three objects, A, B, C [...]. There must, then, be one of the three, at least, say $\mathrm{C}$, which established a relation between the other two, A and $\mathrm{B}$. The result is that $\mathrm{A}$ and $\mathrm{B}$ are in a dyadic relation, and $\mathrm{C}$ may be ignored, even if it cannot be supposed absent. Now, this dyadic relation between A and B, without reference to any third, involves a Secundan. In like manner, in order that there may be a Secundan, so that A and B are in some sense opposed, and neither is swallowed in the other, - or even if only one of them had such a independent standing, it must be capable of being regarded as more or less determinate and positive in itself, and so involves Primanity. This Primanity supposes a Priman element; so that the suggestion that no elements should be Primans is absurd, as is the suggestion that no elements should be Secundans" (EP 2, 364f.).

${ }^{34}$ It is Peirce himself who stressed that the argument presented here was purely a priori. Accordingly, later in the same paper he referred to the argument as follows: "Much might be profitably added to this preliminary a priori study; but even with the greatest compression I shall cover too many of the valuable pages of the Monist" (EP 2, 366). 
philosophy, but they cannot provide what transcendental enterprises aim for, that is, an unquestionable warrant of the factual validity of some propositions. In order to undertake the step from mathematical possibility to factual validity, Peirce thought observation was needed:

The principles and analogies of Phenomenology enable us to describe, in a distant way, what the division of triadic relations must be. But until we have met with the different kinds a posteriori, and have in that way been led to recognize their importance, the a priori descriptions mean little; - not nothing at all, but little (EP 2, 289).

In Peirce's system phenomenology, or phaneroscopy, is the first part of philosophy and so of the positive sciences. It is the science which aims to discern the essential categories of the phenomenon, or phaneron. Thus, as a positive science, it needs observation in order to determine if the a priori expectations justified by mathematical analyses are actually right.

Peirce rejected the possibility that the $a$ priori argument he proposed in his 1905 paper could be considered transcendentally valid. ${ }^{35}$ This follows from his grasp of transcendental methods in general which, as stressed here, accords to what we have called the justificatory account. For Peirce, to provide a transcendental argument would have implied justifying some propositions about the actual world and experience just on the basis of a purely deductive strategy based on a supposedly indubitable point of departure. ${ }^{36}$ The Cartesian appearance of this procedure is manifest, and Peirce, following his anti-Cartesian stance, rejected it. However, if an alternative way of accounting for transcendental enterprises in general (and for the Kantian project in particular) were provided, Peirce's rejection could be proved to be faulty. It is to this new slant on Kant that we now turn.

\section{An alternative reading of Kant and transcendental methods}

Following our reconstruction of justificatory accounts of Kant, his philosophy would have been characterized as being: (a) anti-sceptical in purpose; (b) mentalistic; and (c) deductively developed from an indubitable proposi-

35 Many commentators here follow Peirce in rejecting in this way any attempt to consider Peirce's philosophy in a transcendental way. For example, Kelly Parker stresses: "we saw that Peirce rejected the possibility of transcendental justification for his list of categories. The preceding arguments are the strongest arguments Peirce can offer for the necessity and irreducibility of the concept of combination or thirdness. They are not, however, transcendental. In fact, they are circular in the sense that each one is a deductive argument, and deduction itself presupposes the concept of combination" (Parker 1998, 68).

36 Commentators normally follow Peirce even on this point. For example, André De Tienne notes: "L'argument que Peirce oppose au transcendentalism (surtout Kantien) est donc bien celui d'un objection contre un exigence de justification du travail normal de la conscience" (De Tienne 1996, 96). 
tion to some conclusions involved in it. Concerning point (a), Kant's aim would have been that of guaranteeing the validity of some commonly believed facts, like, for example, the real existence of outer objects, their endurance while unperceived, the truth of causal relations, etc. Consequently, philosophy, as an a priori discipline, would have had a justificatory role with respect to the other sciences, since it would have been the only possible source of warrant with respect to their objects. However, when Kant directly touches on the point concerning the relevance of his critical enterprise with respect to ordinary and scientific knowledge, he seems to discard this approach:

No critique of reason in empirical use was needed, since its principles were subjected to a continuous examination on the touchstone of experience; it was likewise unnecessary in mathematics, whose concepts must immediately be exhibited in concreto in pure intuition, through which anything unfounded and arbitrary instantly becomes obvious (KrV, A 710f./B 738f.).

Following this passage, Kant holds that ordinary and scientific empirical knowledge alike, as well as mathematical knowledge, need not have any justificatory support from philosophical arguments. So, it is unlikely that his first purpose was that of securing concepts commonly used in ordinary experience and science. ${ }^{37}$ Accordingly, Kant did not share the justificatory aim which characterized the philosophical tradition which preceded him. But why did Kant not feel compelled to take into account the adherence of our inner ideas to outer objects?

The perspective which Descartes inaugurated in philosophy was characterized by privileging ideas about inner states in philosophical analysis. The subject, being immediately aware of his mental states, could be confident of their validity, due to their immediate clarity for himself. Justificatory accounts of the transcendental method attribute this mentalistic perspective even to Kant, insofar as in his attempt of refuting the sceptic Kant could accept only those propositions that the sceptic would concede as well. However, Kant was clear in refuting this philosophical standpoint and in stressing the parity of inner and outer senses. Thus, in answering some objections against the ideality of time, he stressed:

37 It is undeniable that Kant considers sceptical issues at some points of his first Critique, for example in his Refutation of Idealism. However, these passages do not have to be considered the basic problem from which he developed his system. On the contrary, his general way of dealing with scepticism is to show that the very perspective which allows the sceptical doubt to arise has to be rejected. Accordingly, Wolfgang Carl states: "But remember that Kant was not concerned with the necessary conditions of our believing something or other; rather his concern was with the necessary conditions of our knowledge. If his reflections were supposed to refute scepticism, he would have been well advised to raise the question whether we have any knowledge at all - instead of taking on the connection between knowledge and its object" (Carl 2006, 187). 
They did not expect to be able to demonstrate the absolute reality of space apodictically, since they were confronted by idealism, according to which the reality of outer objects is not capable of any strict proof; on the contrary, the reality of the object of our inner sense (of myself and my state) is immediately clear through consciousness. The former could have been a mere illusion, but the latter, according to their opinion, is undeniably something real. But they did not consider that both, without their reality as representations being disputed, nevertheless belong only to appearance, which always has two sides, one where the object is considered in itself (without regard to the way in which it is to be intuited, the constitution of which however must for that very reason always remain problematic), the other where the form of the intuition of this object is considered, which must not be sought in the object in itself but in the subject to which it appears, but which nevertheless really and necessarily pertains to the representation of this object (KrV, A 38/B 55).

Here, Kant is stressing that time, as the form of inner sense, has not any privileged reality with respect to space, as the form of outer sense. Both inner and outer senses pertain to the object just as far as it is subject to our form of intuition. In this framework, representations of inner states cannot claim any privileged relation with their objects. ${ }^{38}$ Just like outer representations, they are mediated by the cognitive and sensible constitution of human beings. They cannot be considered privileged departing points from which to start a justifying enterprise. In this respect, Kant left behind the mentalistic standpoint of Cartesian approaches: representations of the self and its inner states have no privileged certainty. ${ }^{39}$ We just need to determine if his claim that inner and outer representations are just appearances necessitated inaugurating a new one.

The parity of inner and outer senses is immediately connected to Kant's empirical realism. In contrasting the empirical idealist standpoint, Kant stresses that there is no need to justify by inference the real existence of the objects our ideas represent. ${ }^{40}$ On the contrary, we can be immediately sure of the objective validity of our representations. He states: "thus the transcendental idealist is an empirical realist, and grants to matter, as appear-

${ }^{38}$ In the Refutation of Idealism Kant argues that outer experience has priority over representations of one's own mental states. This seems to be a stronger position with respect to the parity between inner and outer senses claimed throughout the Aesthetics.

39 By stressing that Kant leaves behind mentalistic perspectives I do not want to say that he gets rid of the problem of the mental. After all, knowledge and representations necessarily concern mind. However, he considers these issues from a very different perspective, leaving behind the problem of the relationship between mental ideas and independent outer objects. It is this latter problem that we have associated with a mentalistic framework privileging representations of inner states in philosophical analysis.

40 As we have already seen, Strawson, who proposes a justificatory account of Kant, does not endorse this idealistic view on perception, giving priority to outer perception. However, as far as this priority to representations of outer objects can be gained only as a result of his argument, his approach to philosophy still treats representations about inner states as possessing a major certainty, insofar as they are not doubted by the sceptic. 
ance, a reality which need not be inferred, but is immediately perceived" $(\mathrm{KrV}, \mathrm{A}$ 371). The recognition of outer objects as really outer is not something that is obtained through inference, but is something that is immediately acknowledged together with their spatiality. As we have seen, Kant does stress that the immediate reality of matter can be claimed just as far as matter is considered as appearance. This led some interpreters to consider Kant's empirical realism as endorsing a quite radical form of idealism. Accordingly, the reality of outer objects would be nothing but the reality of a certain class of mental ideas, that is, those ideas with spatial content. ${ }^{41}$ However, Kant's transcendental idealism and empirical realism were not intended to endorse this view. On the contrary, he just stressed that all our sensible representations had an immediate objective value, inner or outer alike. This objective value is warranted by our capability to identify those representations in a determinate time, or space-time, respectively. ${ }^{42}$ For outer representations, that meant that they immediately represent outer objects as outer, as objects in space. With his transcendental idealism and empirical realism, Kant wanted just to claim that we do not need to go totally beyond our subjective constitution to stress the objective value of our representations. Sensible representations possess an immediate objective value insofar as we can immediately recognize those representations in time, if inner, and in time and space, if outer. Accordingly, conceptual representations can claim objectivity only if they are connected to the a priori forms of sensibility.

Thus, outer representations can be considered as representing immediately their objects, even if, as representations, they possess some characteristics that are inseparable from our subjective standpoint, that is, space and time. In this respect, inner representations are neither in a privileged, nor in an unprivileged position. Even if outer objects, as a class of represented objects, depend on our subjective constitution, this does not mean that outer objects are things that are totally enclosed in our subjective minds at all. Outer objects are out there, even if they depend on our subjective constitution to be represented.

Thus, if Kant did not aim at providing a justification of our ordinary and scientific beliefs and did not endorse a mentalistic perspective in which rep-

${ }^{41}$ Kant's limitation of our knowledge to appearances is often interpreted in this way due to lack of attention for the different senses in which the distinction appearance/thing in itself can be considered. As Henry Allison well stresses, there is an empirical and a transcendental way to intend it, and Kant was interested just in the latter (Allison 1983, 6-8). If in the empirical sense the distinction means: inner mental representation/outer real thing; in the transcendental sense it means: thing as subjected to the conditions of its being represented/thing as not subjected to the conditions of its being represented.

42 It is exactly this character of Kant's thought that Peirce inherited in his doctrine of immediate perception. 
resentations of the self and its inner ideas had a major certainty in the attempt of connecting ideas to the outer reality they represent, it is likely that he did not need to propose a deductive argument of the kind justificatory accounts claim for him. Dieter Henrich has shown how Kant's vocabulary is closer to a legal framework in use in the Germany of his times where Deduktionschriften aimed at recognizing the ground of a right to use something, for example a piece of land or a noble title. ${ }^{43}$ Kant's deductions are not intended to develop an argument from indubitable premises to deductively indubitable conclusions. On the contrary, they aim to trace some elements of our experience to their origin in human reason, the latter broadly conceived. Following what we have just said, Kant did not endorse any one of the features that justificatory accounts of the transcendental method attribute to him. So, if these were not the characteristics of Kant's enterprise, what did his critical philosophy intend to offer?

As was clear in the first quote of this section, Kant's critical attention was not directed toward an assessment of the validity of reason in his normal or scientific use. As the title of his first Critique states, his goal was to determine the possibility and limits of knowledge by pure reason alone. More than aiming toward a justification of our empirical knowledge, a justification that we saw was futile for him, Kant aimed at a critique of speculative and dogmatic philosophy. Kant did not want to determine if our beliefs were adapted for representing reality. On the contrary, he wanted to determine if the purely speculative endeavours of philosophers had any chance of getting settled.

In order to inquire if pure speculative knowledge could actually bring human beings to fruitful results, the aim he reserved for the Dialectic of Pure Reason, Kant had first to undertake a survey of our knowledge ${ }^{44}$ in general, in order to isolate those elements that were not a posteriori derived from particular experience, but were due to our cognitive constitution. Thus, in the Analytic, Kant abstracts the a priori elements which had a peculiar role in experience in general, making the latter possible. The aim of this preliminary study was that of separating the a priori structure of our experience and knowledge; an a priori structure that was not immediately

43 Henrich 1989, 30-34. Here, the appeal to "the ground of a right to use something" can misleadingly lead someone to think of a justificatory purpose. However, Kant's aim has to be considered more explanatory than justificatory. The recognition of these grounds did not mean guaranteeing the right to use them, but just recognizing their function in experience.

44 Paul Guyer uses the word 'knowledge' to translate the Kantian Wissen and 'cognition' to translate Erkenntnis. In the Critique, Wissen has a really strict sense, meaning solid and warranted knowledge. Guyer's translation makes this distinction clear. In this paper I will use the word 'knowledge' in a less rigorous sense, in order to emphasize the objective value of the representations which constitute Kant's first objects of study. 
clear, but needed a consideration of experience and knowledge in general. ${ }^{45}$ In this endeavour, experience did not need to be ignored in order to be vindicated as a final result. ${ }^{46}$ On the contrary, experience in general constitutes the 'datum' from which Kant's analysis starts its abstracting procedure. ${ }^{47}$ This kind of abstraction is quite explicit in passages like this:

So if I separate from the representation of body that which the understanding thinks about it, such as substance, force, divisibility, etc., as well as that which belongs to sensation, such as impenetrability, hardness, color, etc., something from this empirical intuition is still left for me, namely extension and form. These belong to the pure intuition, which occurs a priori, even without an actual object of the senses or sensation, as a mere form of sensibility in the mind ( $\mathrm{KrV}, \mathrm{A} 20 \mathrm{f} . / \mathrm{B} 35)$.

It is clear from this passage that Kant's strategy is not that of obtaining an indubitable starting point and then showing that a set of propositions concerning experience were actually involved in it. From his perspective, experience in general can figure as a departing place, that is, as an object of analysis in which fundamental elements are separated from the rest. ${ }^{48}$

45 In saying that the Analytic is preliminary, I do not want to suggest that it is less important, quite the contrary. In this portion of the book Kant developed all the essential materials on which his system was built. However, these materials cannot be correctly understood unless one also takes into account the general purpose of the book, which was the resolution of dogmatic metaphysical controversies.

46 The a priori structure of knowledge does not function as an indubitable first premise. Accordingly, Graham Bird states: "Kant's a priori principles are fundamental rather than foundational, and do not function as unassailably certain first principles from which our knowledge can be formally deduced, constructed, or justified in a traditional normative, antisceptical epistemology. They function as the governing rules under which our form of experience is necessarily played" (Bird 2006, 261).

47 In this reading of Kant, I am deeply indebted to Bird's interpretation (2006). On this topic, he stresses: "In order to identify and isolate the salient features of experience in a transcendental topic, as a priori or a posteriori, as fundamental Grundelemente or not, as belonging to sense or to understanding, Kant has to take experience as it is. This is not to use it as an antiskeptical resource, but only as a datum from which his philosophical enquiry derives its basic material" (Bird 2006, 235). Arthur Collins touches on a similar point when he claims: "the explanations start from the putative facts and not from special sceptical restrictions. Kant does not refuse to make any use of these ordinary conceptions before they have been certified by a process that relates them to a secure base of evidence" (Collins 1999, 93).

48 It is true that in several places Kant claims to further his analysis 'by reason alone'. That does not mean that he wanted to provide a Cartesian-like argument. On the contrary, he did not have to rely on particular observation and inductive generalization. When he totally neglects experience, he did that to prove that the a priori elements he isolated were actually a priori. The Transcendental Deduction of the categories, for example, was not meant to prove the existence of outer objects using the possibility of self-ascription of thoughts as a departing point. On the contrary, it aimed at proving that a priori concepts were conditions of possibility of experience by showing how there could be no unity in our experience without them (KrV, B 136-138). In doing this, he needed to ignore particular experience to be successful. This step could 
Only when these a priori elements were separated clearly from the rest of our ordinary and scientific knowledge (two domains in which they did not generate any problem and did not need any justification), could Kant show how they were inappropriately used in speculative philosophy, giving rise to irresolvable contradictions. What is important for our purposes is that Kant's a priori enterprise is not meant to move through a series of certainly valid steps in order to secure its results against a sceptical challenge. Kant's transcendental project aims to separate those elements that could not but depend on the a priori structure of our knowledge. In so doing, the first object of study that he faced was not an indubitable a priori starting point, but our knowledge as is commonly understood. This determinate knowledge from which he needed to start could be either the knowledge involved in ordinary experience, or the content of some particular science.

This alternative picture of Kant's method displays a pragmatic dimension of his thought which seems to be compatible with the anti-foundationalism claimed by many pragmatists. Thus, it opens up a new path allowing us to seek similarities between Kant's philosophy and Peirce's. The critical standpoint on pure dogmatic philosophy, the lack of the need to found the objectivity of empirical representations, and empirical realism, are all themes on which many pragmatists would agree. In particular, empirical realism, and its connection with Peirce's immediate perception, seems to be the basis of a philosophical standpoint which considers experience with no justificatory purpose. However, the issue is not so easy to resolve: for example, is Kant's transcendental idealism compatible with pragmatism? I agree with Henry Allison when he stresses that Kant's transcendental idealism cannot be removed from his system without distorting its essential structure. ${ }^{49}$ If we do not understand transcendental idealism as stressing that the world is 'inside our mind', but as stressing that some features of the objects we represent depend on their being in relation with us, then transcendental idealism is inseparable from the alternative reading of Kant here described. This version of transcendental idealism is compatible with a pragmatic standpoint. In fact, no derivation of experience from a purely a priori deductive strategy is at issue, but only the recognition of the representational character of our experience. Thus, it

be identified with the synthetic part of Kant's enterprise. For our purposes, what is important to keep in mind is that this synthetic step is really different, both in strategy and in purpose, from a deductive justificatory argument. Moreover, it is not in contradiction with a previous analysis of experience and knowledge in general.

49 Allison 1983. In contrast to this position, Kenneth Westphal (2003 and 2004) argues that Kant's philosophy actually implies transcendental realism, not transcendental idealism. This would perhaps provide an easier path to finding a link between Kant and Peirce. Westphal (2003) himself suggests that. 
seems that discussing these topics in relationship with Peirce and Kant can shed light on some characters of both transcendental philosophy and pragmatism. However, this is not the aim of this paper. Before any discussion that evaluates either the transcendental character of Peirce's philosophy, or the pragmatic character of Kant's project, what is strongly needed is an evaluation of the exhaustiveness of Peirce's arguments against transcendental methods.

\section{Conclusion}

In this paper I have presented two very different accounts of Kant and the transcendental method. These two ways of accounting for Kant's project have been already recognized by other commentators. However, they have never been used to ascertain if Peirce was a transcendental philosopher. We have discovered that Peirce's criticisms of the transcendental method are directed against justificatory accounts, since these criticisms address what I have called characteristics (a), (b) and (c) of the justificatory account of Kant. If this is true, attributing to Peirce a kind of transcendental method in line with the alternative account just described would not conflict with his direct criticisms, since the alternative account does not endorse any one of those characteristics. I think this is an essential discovery for any inquiry into the transcendental character of Peirce's thought, either if it seeks to reject transcendental readings of Peirce or if it seeks to propose one. In both cases, knowing that Peirce's own criticisms are not definitive is essential.

Yet, I do not think that the results of this paper are only negative, that is to say they do not allow us only to say that Peirce's arguments against transcendental philosophy are not ultimate. In the first instance, we can stress that a justificatory transcendental project would be in conflict with those criticisms and that the only kind of transcendental philosophy attributable to Peirce is of the alternative kind. Moreover, we saw that the alternative account of Kant cannot be separated from transcendental idealism. This means that if we wish to find a transcendental method in Peirce's work we would have also to stress a kind of transcendental idealism for his philosophy. Accordingly, his semeiotic was surely intended to display features of our thinking that depend on the representative nature of signs. If the way in which we represent objects is dependent upon some general features of the signs we use, it means that those objects appear as they are also in so far as they stand in a relation to us through those signs. This seems to agree with a form of transcendental idealism. However, Peirce also endorsed a form of metaphysical realism that can hardly go together with transcendental idealism. He stressed that we are successful in knowing nature as far as nature and thought follow the same rules. 
In my view, Peirce uses procedures of analysis that can be read in a transcendental way. ${ }^{50}$ As far as these procedures have to be of the alternative kind here described, they must entail a form of transcendental idealism. In particular, Peirce's semeiotic and its disentanglement of the relational structure which allows our signs to be representative would be a territory to investigate in depth. Moreover, I am convinced that Peirce's method of 'prescision' displays deep similarities with Kant's abstracting procedure. This is not an inquiry which I will pursue in this paper, though, but is a challenge that will be met in a further paper. The conclusion that Peirce's criticisms would not conflict with a transcendental reading of his thought in accordance with the alternative account of Kant here presented fulfils the purpose of this study. ${ }^{51}$

Works by Kant

KrV Critique of Pure Reason. Eds. and trans. P. Guyer/A. Wood. Cambridge 1998. ['A' refers to the paging of the first original edition (1781) and 'B' to the paging of the second original edition (1787).]

PC Philosophical Correspondence 1759-99. Ed. and trans. A. Zweig. Chicago 1986.

Prol. Prolegomena to Any Future Metaphysics. Ed. and trans. G. Hatfield. Cambridge 2004. [Cited by page number of Vol. IV of the German "Akademie" edition of Kant's gesammelte Schriften, Berlin 1902ff.]

Works by Peirce

CP Collected Papers of Charles Sanders Peirce. Eds. C. Hartshorne/P. Weiss (volumes 1-6), and A. Burks (volumes 7-8). Harvard 1931-1958. [Cited by volume and paragraph number.]

EP The Essential Peirce. Ed. The Peirce Edition Project. Bloomington 1992-1998. [Cited by volume and page number.]

NEM The New Elements of Mathematics by Charles S. Peirce. Ed. C. Eisele. The Hague 1976. [Cited by volume and page number.]

W Writings of Charles S. Peirce: a Chronological Edition. Ed. The Peirce Edition Project. Bloomington $1982 \mathrm{ff}$. [Cited by volume and page number.]

Abrams, J. J. 2004. "Peirce, Kant, and Apel on Transcendental Semiotics: The Unity of Apperception and the Deduction of the Categories of Signs". Transactions of the Charles S. Peirce Society 40, 627-677.

Allison, H. E. 1983. Kant's Transcendental Idealism: An Interpretation and Defense. New Haven.

50 In a forthcoming paper, I argue that Peirce's method of 'prescision' can be read as a kind of transcendental method (see Gava 2011). For a transcendental reading of Peirce's aesthetic ideal and regulative principles which compares them to Kant's regulative ideas and principle of purposiveness, see Gava 2008.

51 I would like to thank Alfredo Ferrarin, Christopher Hookway, Vincent Colapietro, Graham Bird, and the referees of the Archiv für Geschichte der Philosophie for their useful comments on previous versions of this paper. 
Apel, K. O. 1981. Charles S. Peirce. From Pragmatism to Pragmaticism. Amherst.

Bird, G. 2006. The Revolutionary Kant: A Commentary on the Critique of Pure Reason. Chicago.

Carl, W. 2006. "Kant's refutation of Problematic Idealism: Kantian Arguments and Kant's Arguments against Skepticism”. In A Companion to Kant. Ed. G. Bird. Malden, 182-191.

Christensen, C. B. 1994. "Peirce's Transformation of Kant". The Review of Metaphysics 48, 91-120.

Collins, A. W. 1999. Possible Experience: Understanding Kant's Critique of Pure Reason. Berkeley.

Cooke, E. 2006. Peirce's Pragmatic Theory of Inquiry: Fallibilism and Indeterminacy. London.

De Tienne, A. 1996. L'analytique de la représentation chez Peirce: la genèse de la théorie des categories. Bruxelles.

Esposito, J. 1980. Evolutionary Metaphysics: The Development of Peirce's Theory of Categories. Athens.

Gava, G. 2008. "The Purposefulness in our Thought: A Kantian Aid to Understanding Some Essential Features of Peirce". Transactions of the Charles S. Peirce Society 44, 699-727.

-. 2011. "Peirce's 'Prescision' as a Transcendental Method". International Journal of Philosophical Studies 19 (forthcoming).

Henrich, D. 1989. "Kant's Notion of a Deduction and the Methodological Background of the First Critique" In Kant's Transcendental Deductions: The 'Three Critiques' and the 'Opus Postumum'. Ed. E. Förster. Stanford, 29-46.

Hookway, C. 2000. Truth, Rationality, and Pragmatism: Themes from Peirce. Oxford.

Midtgarden, T. 2007. "Peirce's Epistemology and its Kantian Legacy: Exegetic and Systematic Considerations". Journal of the History of Philosophy 45, 577-601.

Misak, C. 1994. "Pragmatism and the Transcendental Turn in Truth and Ethics". Transactions of the Charles S. Peirce Society 30, 739-775.

Murphey, M. G. 1961. The Development of Peirce's Philosophy. Harvard. Second edition Indianapolis 1993.

Oehler, K. 1987. "Is a transcendental Foundation of Semiotics Possible? A Peircean Consideration". Transactions of the Charles S. Peirce Society 23, 45-63.

-. 1995. "A Response to Habermas". In Peirce and Contemporary Thought. Ed. K. L. Ketner. New York, 267-271.

Parker, K. A. 1998. The Continuity of Peirce's Thought. Nashville.

Pihlström, S. 2003. Naturalizing the Transcendental: A Pragmatic View. Amherst.

Short, T. L. 2000. "Peirce on the Aim of Inquiry: Another Reading of 'Fixation"”. Transactions of the Charles $S$. Peirce Society 36, 1-23.

-. 2007. Peirce's Theory of Signs. Cambridge.

Strawson, P. F. 1966. The Bounds of Sense: An Essay on Kant's Critique of Pure Reason. London.

Stroud, B. 1994. "Kantian Arguments, Conceptual Capacities and Invulnerability”. In Kant and Contemporary Epistemology. Ed. P. Parrini. Dordrecht, 231-252.

Westphal, K. R. 2003. "Can Pragmatic Realists Argue Transcendentally?" In Pragmatic Naturalism and Realism. Ed. J. R. Shook. Amherst, 151-175.

-. 2004. Kant's Transcendental Proof of Realism. Cambridge. 